\title{
The Impact of the Mt. Pinatubo Eruption on the Climate of the Northern Hemisphere
}

\author{
Osamu MORITA*, Yuji NAKANO ${ }^{* *}$ and Kohichi MUROTANI ${ }^{* * *}$ \\ "Department of Earth and Planetary Sciences, Faculty of Science, Kyushu University, Fukuoka 812-8581, Japan \\ "Faculty of Economy, Shiga University, Hikone 522-8522, Japan \\ "**Fukuoka District Meteorological Observatory, Japan Meteorological Agency, Fukuoka 810-0052, Japan
}

\begin{abstract}
The eruption of Mt. Pinatubo in the Philippines (15N, 120E) on June 15, 1991 was the largest one in the 20th century. The large amount of sulfur dioxide injected into the lower stratosphere caused global climate variations for the 2 3 years after the eruption. As observations of sulfate aerosols were continued for a long period before and after the eruption (e.g. SAGE II, McCormic and Veiga, 1992; TOMS, Bluth et al., 1992), it was possible to analyze the relation between the surface temperature anomaly (hereafter designated as STA) and the sulfate aerosol density (hereafter designated as $\mathrm{SAD}$ ) which directly affected the radiation process. By these fortunate situations it was possible to make clear the relation between SAD and STA using traditional correlation analysis and the causality analysis newly developed by one of the authors (Nakano, 1995).

The results of two statistical methods show that STA is most affected by SAD at the latitude belt of 30 40N. In general, it is recognized that the surface temperature response due to volcanic impacts is slow, and the effects become prominent after 1 or 2 years following the eruptions. However, we will demonstrate here that the surface temperature response is rather quick, considering the chemical reaction time for producing sulfate aerosols (about a half year) and the parasol effect of SAD reaching maximum at the highest solar zenith angle. The time lag is only 1 2 months, which is the same as the seasonal march due to the thermal inertia of the large continents. Key words: Causality analysis, Correlation analysis, ENSO, Mt. Pinatubo eruption, Sulfate aerosol
\end{abstract}

\section{Introduction}

The enuption of the Mt. Pinatubo in 1991 was the largest one in the 20th century, and sulfur dioxide of 20 30 mega-tons was injected in the lower stratosphere (Bluth et al, 1992; McCormick and Veiga, 1992). The magnitude of the eruption was very large and the DVI (dust veil index) was 1000 (Robock and Mao, 1995; Jones and Kelly, 1996). The DVI was defined by Lamb (1970) as the measure of the volcanic impact on the climate system. The reference value of DVI is 1000 which is defined by the explosive eruption of Krakatau in 1883. Only two single eruptions reached the value 1000 in DVI throughout 19th and 20th centuries, i.e. the case of Krakatau and Mt. Pinatubo. A series of eruptions in a relatively short period in Latin America covered 1000 of DVI in 1902: Pelee (Montagne Is., West Indies, DVI=100) Soufriere (St. Vincent Is., West Indies, DVI=300), Santa Maria (Guatemala, DVI=600). Sulfur dioxide released by Mt. Pinatubo reacted with hydroxyls in the atmosphere, and formed a hydrated sulfuric acid aerosol, which stayed in the lower stratosphere for a few years. The surface density of the sulfuric acid aerosol reached the maximum value from December 1991 to January 1992. It decreased exponentially afterwards, and the effect remained until 1994. The e-folding time of SAD was about 1 year (Fiocco et al., 1996). It increased the terrestrial albedo (parasol effect) and played the primary role of the cool summers in the Northern Hemisphere in 1992 and 1993. It is the purpose of this study to verify the above mentioned process by the newly developed statistical analysis.

Many studies have been done on volcanic effects on the climate which are divided into analyses of STA and those of the temperature variation of the lower stratosphere. Many studies about the effect of a single volcanic eruption on the lower stratosphere have been made from the following viewpoints: (1) The response of the stratosphere is so quick that the causal relation is obvious. (2)The volcanic effect always appears as a positive temperature anomaly, and the absolute value of it is large (10K in the case of major eruptions as $\mathrm{El}$ Chichon and the Mt. Pinatubo). (3) The climate signal comparable to the volcanic signal in the tropical lower stratosphere is only the temperature deviation by quasi-biennial oscillations (Parker and Branscombe, 1983: Angell and Korshover, 1983a,b: Angell,1996: Labitzke and van Loon,1996)

The climate response of the troposphere is complicated for the following reasons: (1) The volcanic impacts appear a half year after eruptions and continue for $1 \sim 2$ years. (2) The temperature response is not simple as the temperature anomaly is generally negative but becomes positive at higher latitudes of the winter hemisphere. (3) Further, the volcanic signal is so weak and comparable to other climate signals that a statistical technique called 'superposed epoch analysis' 
(SEA) was employed in many studies (Kelly and Sear, 1984: Sear et al., 1987: Robock and Mao,1995: Jones and Kelly,1996). The SEA technique enables to pick up a weak signal embedded in the noise level. Robock and Mao (1995) studied in detail superposed surface temperature responses of 6 major volcanic eruptions (Krakatau, Santa Maria, Katmai, Agung, El Chichon, Pinatubo), and isolated the pure volcanic forcing on the STA by removing the ENSO signal by the linear regression method. Jones and Kelly (1996) pointed out that the superposed surface temperature deviation of 4 historical volcanic eruptions in the tropics resembled the response of the Mt. Pinatubo eruption. Their results show that the magnitude of the eruption of $\mathrm{Mt}$.' Pinatubo was so large that it was possible to obtain statistically significant results in spite of only a single eruption. In addition, the global distribution of the physical quantities relating to radiation impacts (the surface density of sulfur acid aerosol and the optical depth of the atmosphere) were measured continuously for a long period by artificial satellites.

It was then possible to make clear the cause and result relationship between the radiation forcing of SAD and STA in this study.

\section{The Data Used for This Study}

Data used for this study are part of the NCAR/NCEP reanalysis data which are the monthly mean temperatures of $144 \times 73$ global grid points at $1000 \mathrm{hPa}$ level, whose data period is from January 1980 to December 2000. Another data source is the monthly mean surface density of sulfuric acid aerosol observed by SAGE II satellite at three latitude belts $(20 \sim 30 \mathrm{~N}$, $30 \sim 40 \mathrm{~N}$ and $40 \sim 50 \mathrm{~N}$ ) from January 1985 to December 1996. The temperature anomaly is calculated by extracting the reference value from the original data; these reference values at $144 \times 73$ grid points were obtained by taking the mean through all data periods for each month. This procedure removed the seasonal variation from the monthly mean temperature data. Next, the mean values are obtained along a latitude for every 2.5 degrees from $20 \mathrm{~N}$ to $50 \mathrm{~N}$. Finally, latitude belt mean data are obtained for three latitude belts $(20 \sim 30 \mathrm{~N}, 30 \sim 40 \mathrm{~N}, 40 \sim 50 \mathrm{~N})$ from latitude mean data taking into account the geometrical factor.

An example of SAD and STA of 30 40N latitude belts is shown in Fig.1, where STA is shown in two ways, one is monthly mean data and the other is 15 months running mean data.

\section{Methods of Analyses and Results}

The methods of time-sequential data analyses employed in this study are the traditional crosscorrelation analysis and the causality analysis, which were developed by Nakano (1995) based on the theory of the $\mathrm{KM}_{2} \mathrm{O}$-Langevin equation by Okabe (Okabe and Nakano, 1991).

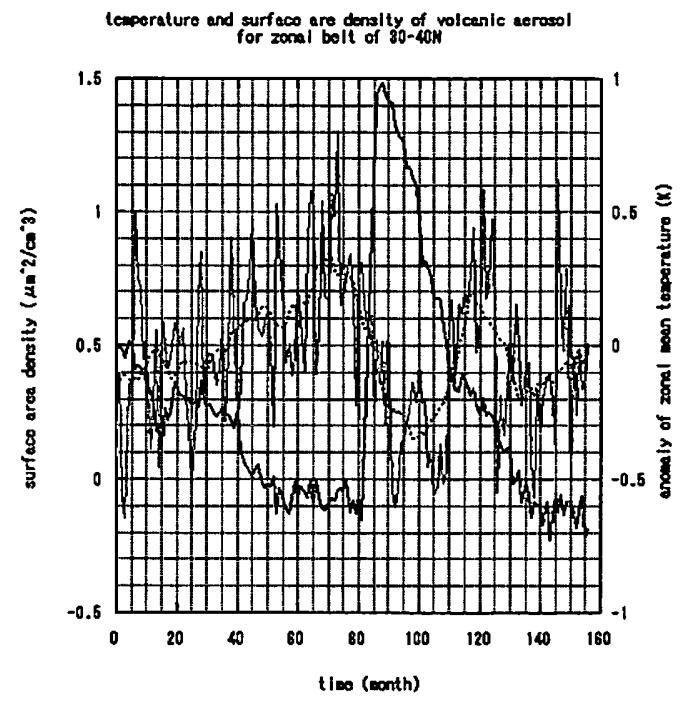

Fig.1 Time sequence of SAD and STA from January 1985 to December 1996.

\subsection{The analyses for latitude belts}

The results of using these two time-sequential data analyses are summarized in Table 1 . From the results of causality analysis, it is shown that STA of all three latitude belts are affected by SAD in each latitude belt. The STA of the 30 40N belt is most intensely affected by SAD, STA of the $20 \sim 30 \mathrm{~N}$ belt is secondary affected by SAD, and STA of the $40 \sim 50 \mathrm{~N}$ belt is only weakly affected by SAD. Very large cross-correlation coefficients with over $98 \%$ confidential levels are obtained for all three latitude belts. Time lags in month units become larger as the latitudes become higher, and the time lag of the highest latitude belt is 8 months. The maximum value of SAD at the latitude belt of the 20 30N appears in December 1991, and SAD of the $40 \sim 50 \mathrm{~N}$ belt reached the maximum in January 1992. Therefore, the cause of the time lag in these correlation analyses should be attributed not to the lag of poleward diffusion of volcanic sulfate aerosol but to the lag due to the seasonal march. This fact will be seen more clearly from the results in the analyses of 13 latitude circles in the next subsection.

Table 1. Correlation coefficients and the percentage of the causal value at three latitude belts.

\begin{tabular}{cccc}
\hline latitude belt & correlation & time lag & causal value \\
\hline $40-50 \mathrm{~N}$ & -0.38820 & 8 & $90.60 \%$ \\
$30-40 \mathrm{~N}$ & -0.46452 & 5 & $95.70 \%$ \\
$20-30 \mathrm{~N}$ & -0.46498 & 1 & $93.10 \%$ \\
\hline
\end{tabular}

\subsection{The analyses for 13 latitude circles}

In this subsection, STA averaged along the 13 latitude circles from $20 \mathrm{~N}$ to $50 \mathrm{~N}$ by every 2.5 degrees are compared with SAD. The SAD data are available only for every 10 degrees, but we considered that the 
distribution of SAD is representative for over wide latitudes because the time lag is only one month between the maximum month of $\mathrm{SAD}$ at $20-30 \mathrm{~N}$ and that of SAD at $40 \sim 50 \mathrm{~N}$. The results are shown in Table 2.

From the results of causality analysis, it is shown that STA from $27.5 \mathrm{~N}$ to $35 \mathrm{~N}$ are strongly influenced by SAD. STA of $20 \mathrm{~N}, 22.5 \mathrm{~N}$ and $50 \mathrm{~N}$ are not affected by SAD. And from the results of correlation analysis, there are negative correlation between STA and SAD in all 13 latitudes with a $98 \%$ confidential level. A reasonable relationship between the causality analysis and the correlation analysis is found again. Time lags in correlation analysis become larger at the higher latitudes, and the time lag at $50 \mathrm{~N}$ is 8 months. As SAD at $40 \sim 50 \mathrm{~N}$ reaches the maximum at January 1992, STA at 50N latitude circle turns out to be most influenced in September 1992. Then it is obvious that the cooling latitude is moving pole-ward owing to the seasonal march. Namely, the cooling effect appears most prominently at the time of the maximum solar zenith angle, which is consistent with the results obtained by Robock and Mao (1995). It is unreasonable that the time lag is -2 months in lower latitudes ( $20 \mathrm{~N}$ and $22.5 \mathrm{~N}$ ). As is discussed in a later section, this discrepancy will be solved by removing the impact of the ENSO signal from STA.

Table2. Correlation coefficients and the percentage of the causal value at 13 latitudes.

\begin{tabular}{cccc}
\hline latitude & correlation & time lag & causality \\
\hline $50.0 \mathrm{~N}$ & -0.34263 & 8 & $88.50 \%$ \\
$47.5 \mathrm{~N}$ & -0.37238 & 8 & $89.90 \%$ \\
$45.0 \mathrm{~N}$ & -0.38929 & 7 & $91.70 \%$ \\
$42.5 \mathrm{~N}$ & -0.35962 & 7 & $86.20 \%$ \\
$40.0 \mathrm{~N}$ & -0.46020 & 8 & $82.20 \%$ \\
$37.5 \mathrm{~N}$ & -0.42984 & 7 & $91.60 \%$ \\
$35.0 \mathrm{~N}$ & -0.47768 & 5 & $96.90 \%$ \\
$32.5 \mathrm{~N}$ & -0.46903 & 5 & $95.40 \%$ \\
$30.0 \mathrm{~N}$ & -0.48260 & 3 & $97.00 \%$ \\
$27.5 \mathrm{~N}$ & -0.49784 & 2 & $98.20 \%$ \\
$25.0 \mathrm{~N}$ & -0.44617 & 1 & $93.40 \%$ \\
$22.5 \mathrm{~N}$ & -0.36435 & -2 & $79.20 \%$ \\
$20.0 \mathrm{~N}$ & -0.31284 & -2 & $64.50 \%$ \\
\hline
\end{tabular}

\subsection{The analyses of grid point data}

Making use of the two methods of time sequential data analyses, we examined the relation between SAD and STA at $144 \times 13$ grid points. The regions where the causal value exceeds $90 \%$ are northern Africa, the Middle East, western Russia, the middle Pacific Ocean, southern Canada, and the northern United States.

The correlation analysis is also performed for 144 $\times 13$ grid points. In this analysis, the time lag is fixed at each latitude. The fixed time lag was chosen so that the cross correlation coefficients take the largest absolute value for the latitude mean STA. Negative correlation is observed between SAD' and STA at almost all regions except for the Tropical eastern Pacific Ocean.

\section{Discussions and Conclusions}

\subsection{Removal of the ENSO signal}

The ENSO signal involved in STA of the global 144 $\times 73$ grid points is removed by making use of the $\mathrm{KM}_{2} \mathrm{O}$-Langevin equation. The time series of the Southern Oscillation Index (SOI) is employed as the measure of ENSO. Mean values are calculated again for 13 latitudes from $20 \mathrm{~N}$ to $50 \mathrm{~N}$ and for 3 latitude belts of $20 \sim 30 \mathrm{~N}, 30 \sim 40 \mathrm{~N}$ and $40 \sim 50 \mathrm{~N}$ from the new data set. In a similar way as with the last section, two data analyses are performed for these data, and the results are as follows.

\subsection{The analyses of data for 13 latitudes}

The results by two time sequential data analyses are summarized in Table 3. In section 3.2 , we have obtained the unreasonable results that time lag is -2 months at the lowest two latitude circles, $20 \mathrm{~N}$ and $22.5 \mathrm{~N}$. However, after removing the ENSO signal, time lags of the lowest two latitudes become one month. Both the correlation coefficients and the percentage of the causal value become larger at the lowest two latitudes. The correlation coefficients still exceed the significant level, while the percentage of the causal values becomes lower than $90 \%$ at all 13 latitudes. Though the correlation coefficients do not show a monotonic behavior, they almost become larger as the latitude becomes lower.

Table3. Same as Table 2. except for the removal of the ENSO signal from STA.

\begin{tabular}{cccc}
\hline latitude & correlation & time lag & causality \\
\hline $50.0 \mathrm{~N}$ & -0.23977 & 8 & $67.80 \%$ \\
$47.5 \mathrm{~N}$ & -0.26233 & 8 & $65.10 \%$ \\
$45.0 \mathrm{~N}$ & -0.26907 & 8 & $64.60 \%$ \\
$42.5 \mathrm{~N}$ & -0.23008 & 8 & $49.10 \%$ \\
$40.0 \mathrm{~N}$ & -0.22586 & 8 & $55.10 \%$ \\
$37.5 \mathrm{~N}$ & -0.27804 & 7 & $62.80 \%$ \\
$35.0 \mathrm{~N}$ & -0.32972 & 5 & $72.50 \%$ \\
$32.5 \mathrm{~N}$ & -0.32852 & 5 & $64.30 \%$ \\
$30.0 \mathrm{~N}$ & -0.36384 & 3 & $77.00 \%$ \\
$27.5 \mathrm{~N}$ & -0.40220 & 2 & $84.90 \%$ \\
$25.0 \mathrm{~N}$ & -0.40659 & 1 & $86.10 \%$ \\
$22.5 \mathrm{~N}$ & -0.39042 & 1 & $89.30 \%$ \\
$20.0 \mathrm{~N}$ & -0.39297 & 1 & $89.30 \%$ \\
\hline
\end{tabular}

\subsection{The correlation analyses of grid point data}

The correlation analyses are again performed for the $144 \times 13$ grid points STA. Though the magnitude of 
the correlation coefficients diminishes, the region of positive correlation still exists at the Tropical eastern Pacific Ocean (the figure is not shown). This fact indicates that the removal of the ENSO signal from the STA is not yet sufficient. The regions of negative correlation of -0.2 - 0.4 extend from northern Africa to the Middle East, southern Asia, the Tropical western and middle Pacific Ocean, southern Canada, and the Tropical eastern Atlantic Ocean. These regions of negative correlation correspond well to the cooling regions obtained by Jones and Kelly (1996) who made superposed epoch analysis for four tropical volcanic eruptions.

\subsection{Conclusions}

The following are the conclusions from this study:

(1) The magnitude of the Mt. Pinatubo enuption was so large that the evaluation of the volcanic impact to the surface temperature anomaly was possible, despite being only a single event. As the direct measurement of sulfate aerosol had been performed for a long period including the Mt. Pinatubo eruption, it was able to clarify the surface temperature response by the radiation forcing due to volcanic aerosol.

(2) Analyzing the relationship between SAD and STA at three latitude belts $(20 \sim 30 \mathrm{~N}, 30 \sim 40 \mathrm{~N}, 40 \sim 50 \mathrm{~N})$ by the causality and the correlation analyses, it turned out that STA of the 30 40N latitude belt was mostly affected by $\mathrm{SAD}$.

(3) It has been the common recognition from many studies so far that the surface temperature response due to volcanic impacts is slow and the effects become prominent after 1 or 2 years following the eruptions. However, it has become clear from the present study that the surface temperature response is rather quick considering the chemical reaction time of sulfate aerosol (about a half year) and the parasol effect of $\mathrm{SAD}$ reaching maximum at the highest solar zenith angle. The time lag is only $1 \sim 2$ months, which is the same lag as with the seasonal march.

(4) The causality and the correlation analyses are performed for STA from which the ENSO signal has been removed by use of the $\mathrm{KM}_{2} \mathrm{O}$-Langevin equation. The result shows that STA of lower latitudes are affected more by SAD.

(5) The analyses of the original STA show that STA of mid-latitude belts of $27.5 \sim 35 \mathrm{~N}$ is mostly affected by $\mathrm{SAD}$. Therefore, it is reasonable to consider that the global weather extremes of the second summer following the Mt. Pinatubo eruption was a cooperative phenomenon of the volcanic eruption and the ENSO Warm Event.

\section{References}

Angell, J.K. and Korshover, J., 1983a: Global temperature variations in the troposphere and stratosphere. Mon. Wea. Rev., 111, 901-921.

Angell, J.K. and Korshover, J., 1983b: Comparison of stratospheric warmings following Agung and
Chichon. Mon. Wea. Rev., 111, 2129-2135.

Angell, J.K., 1996: Stratospheric temperature after volcanic eruption. The Mount Pinatubo Eruption: Effects on the Atmosphere and Climate (ed. by Fiocco, G., Fua, D. and Visconti, G.), Springer, Berlin, pp. 83-93.

Bluth, G.J.S., Doiron, S.D., Schneider, C.C., Krueger, A.J. and Walter, L.S., 1992: Global tracking of the $\mathrm{SO}_{2}$ clouds from the June, 1991 Mount Pintubo eruptions. Geophys. Res. Lett., 19, 151-154.

Fiocco, G., Cacciani, M., di Sarra, A.D., Fua, D., Colagrande, P., De Benedetti, G., Di Girolamo, P. and Viola, R., 1996: The evolution of the Pinatubo stratospheric aerosol layer observed by Lidar at South Pole, Rome, Thule: a summary of results. The Mount Pinatubo Eruption: Effects on the Atmosphere and Climate (ed. by Fiocco, G., Fua, D. and Visconti, G.), Springer, Berlin, pp. 127-139.

Fujita, T., 1985: The abnormal temperature rises in the lower stratosphere after the 1982 eruption of the volcano El Chichon, Mexico. Papers Meteor. and Geophys., 56, 495-507.

Jones, P.D. and Kelly, P.M., 1996: The effect of tropical explosive volcanic eruptions on surface air temperature. The Mount Pinatubo Eruption: Effects on the Atmosphere and Climate (ed. by Fiocco, G., Fua, D. and Visconti, G.), Springer, Berlin, pp. 95111.

Kelly, P.M. and Sear, C.B., 1984: Climatic impact of explosive volcanic explosions. Nature, 311, 740-743.

Lamb, H.H., 1970: Volcanic dust in the atmosphere, with a chronology and assessment of its meteorological significance. Philos. Trans. R. Soc. London A, 266, 425-533.

Labitzke, K. and van Loon, H., 1996: The effect on the stratosphere of three tropical volcanic eruptions. The Mount Pinatubo Eruption: Effects on the Atmosphere and Climate (ed. by Fiocco, G., Fua, D. and Visconti, G.), Springer, Berlin, pp. 113-125.

McCormick, M.P. and Veiga, R.E., 1992: SAGE II measurements of early Pinatubo aerosols. Geophys. Res. Lett., 19, 155-158.

Nakano, Y., 1995: On a causal analysis of economic time series. Hokkaido Mathematical Journal, 23, 179-213.

Okabe, Y. and Nakano, Y., 1991: The theory of $\mathrm{KM}_{2} \mathrm{O}$-Langevin equations and its applications to data analysis (I): Stationary analysis. Hokkaido Mathematical Journal, 20, 45-90.

Parker D.E. and Branscombe J.L., 1983: Stratospheric warming following the El Chichon eruption. Nature, 301, 406-408

Robock, A. and Mao J., 1995: The volcanic signal in surface temperature observations. J. Climate, 8 , 1086-1103.

Sear, C.B., Kelly, P.M., Jones, P.D. and Goodess, C.M., 1987: Global surface-temperature responses to major volcanic explosions. Nature, 330, 365-367. 